\title{
Sickle Cell Trait, Hemoglobin Levels and Anemia among Black Patients with Predialysis Chronic Kidney Disease: A Post Hoc Analysis
}

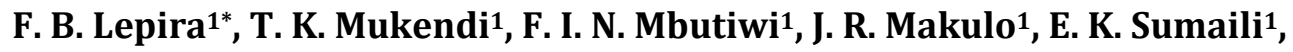 \\ P. K. Kayembe ${ }^{2}$, N. M. Nseka ${ }^{1}$ \\ ${ }^{1}$ Division of Nephrology, University of Kinshasa Hospital, Kinshasa, Democratic Republic of Congo \\ ${ }^{2}$ Kinshasa School of Public Health, University of Kinshasa, Kinshasa, Democratic Republic of Congo \\ Email: "lepslepira@yahoo.fr
}

Received 20 June 2016; accepted 8 August 2016; published 11 August 2016

Copyright (C) 2016 by authors and Scientific Research Publishing Inc.

This work is licensed under the Creative Commons Attribution International License (CC BY).

http://creativecommons.org/licenses/by/4.0/

(c) $\underset{\mathrm{EY}}{\mathrm{O}}$ Open Access

\begin{abstract}
Objective: To assess the relationship between SCT, hemoglobin levels and anemia in CKD black patients. Method: A post-hoc analysis of data from 188 patients, enrolled in a cross-sectional study of sickle cell trait (SCT) and chronic kidney disease (CKD), was performed to assess the relationship between SCT, hemoglobin (Hb) levels and anemia defined as $\mathrm{Hb}<12 \mathrm{~g} / \mathrm{dl}$ in men and $<11 \mathrm{~g} / \mathrm{dl}$ in women. Student $t$ test, Mann Whitney and Chi square test were used as appropriate for different comparisons. $P<0.05$ defined the level of statistical significance. Results: SCT (HbAS) and normal hemoglobin (HbAA) were present in 39 (21\%) and 149 (79\%) CKD patients, respectively. Despite similar estimated GFR (eGFR) and age, HbAS patients had significantly lower Hb levels (8.8 $\pm 1.8 \mathrm{vs}$ $10 \pm 2.2 \mathrm{~g} / \mathrm{dl} ; \mathrm{p}=\mathbf{0 . 0 0 1})$ and a higher proportion of anemia $(95 \%$ vs $72 \%, p=0.001)$. In multiple linear regression analysis, eGFR, BMI, SBP and SCT emerged as independent determinants of Hb levels. The presence of SCT was associated with $1.185 \mathrm{~g} / \mathrm{dl}$ decrease in Hb levels. Conclusion: In the present case series, SCT was associated with lower Hb levels suggesting its potential contribution to the pathogenesis of CKD-associated anemia.
\end{abstract}

\section{Keywords}

Anemia, Sickle Cell Trait, Chronic Kidney Disease, Black Africans

\footnotetext{
${ }^{*}$ Corresponding author.
}

How to cite this paper: Lepira, F.B., Mukendi, T.K., Mbutiwi, F.I.N., Makulo, J.R., Sumaili, E.K., Kayembe, P.K. and Nseka, N.M. (2016) Sickle Cell Trait, Hemoglobin Levels and Anemia among Black Patients with Predialysis Chronic Kidney Disease: A Post Hoc Analysis. World Journal of Cardiovascular Diseases, 6, 258-264. http://dx.doi.org/10.4236/wjcd.2016.68029 


\section{Introduction}

African American patients with end-stage renal disease (ESRD) have been reported to have lower hemoglobin levels at the start of dialysis compared to other racial or ethnic groups [1] [2]. This difference in hemoglobin levels persists into the first year of dialysis despite similar treatment protocols [2]. Furthermore, patients receiving chronic dialysis ( $\geq 90$ days) require higher doses of erythropoietin-stimulating agents (ESA) to achieve similar hemoglobin levels [3]. Although disparities in access to predialysis care have been advocated, they do not fully explain the persistence of lower hemoglobin levels in Blacks [3]. An alternative or additional explanation could be that lower hemoglobin levels and higher ESA dosing may reflect an underlying hemoglobinopathy [3]. Indeed, a higher prevalence of heterozygosity for hemoglobin S (HbAS) and C (HbAC) has been already reported in African Americans with ESRD receiving dialysis [4]. Although typically considered as a benign carrier state, individuals with HbAS or HbAC may experience clinical complications due to changes to red-cell rigidity under situations of stress [5] that could lead to low grade sickling and hemolysis. Uremic toxins may alter erythrocytes and predispose to sickling of red blood cells containing HbAS [6]. Sickle cell trait (SCT) has been also shown to be potentially prothrombotic [7]. Furthermore, chronic kidney disease (CKD) black patients bearing HbAS have been reported to be resistant to ASE and require thus higher doses of these agents compared to other race/ethnic groups [4]. Bearing in mind these pathophysiological changes, one might expect HbAS to be common in patients with CKD and particularly influential in the pathogenesis and treatment of CKD-associated anemia [8]. Therefore, the identification of SCT in patients with CKD could have therapeutic and prognostic implications [8].

In the Democratic Republic of the Congo, the prevalence of CKD is estimated to be of $12 \%$ [9]. In clinical settings, three quarters of patients are referred late at CKD stages 4 or 5 with anemia as one the common clinical findings [10]. The prevalence of SCT is reported to be of $20 \%$ [11]. If the relationship between SCT and CKD has been already evaluated [12], it is not yet the case for that of SCT with anemia in CKD patients. Therefore, the aim of the present post hoc analysis was to determine the prevalence of SCT and its association with anemia in CKD patients prior to dialysis. We hypothesized that HbAS would be more frequent in CKD patients and predispose to lower $\mathrm{Hb}$ levels.

\section{Patients and Methods}

To assess the prevalence of SCT and its association with anemia in patients with CKD, we performed a post hoc analysis of data from 188 patients enrolled in a cross-sectional study of the relation between CKD and SCT carried out at secondary (General Hospital of Kinshasa, Saint Joseph Hospital Kinshasa) and tertiary (University of Kinshasa Hospital) healthcare settings from 30 April to 24 August 2012. The details of the original study have been already described elsewhere [12]. In brief, Hb genotypes using high performance liquid chromatography, serum creatinine, hemoglobin levels, serum lipids, plasma glucose and dipstick proteinuria were retrieved from each patient's file. Estimated glomerular filtration rate (eGFR, $\mathrm{ml} / \mathrm{min} / 1.73 \mathrm{~m}^{2}$ ) was calculated from serum creatinine using the abbreviated Modification of Diet in Renal Disease equation (MDRD) [13]; chronic kidney disease (CKD) was defined as GFR $<60 \mathrm{ml} / \mathrm{min} / 1.73$ or dipstick proteinuria $\geq 1+$ and stratified according to Kidney Disease Outcome Quality Initiative [14]. Anemia was defined as $\mathrm{Hb}<12 \mathrm{~g} / \mathrm{dl}$ in men or $<11 \mathrm{~g} / \mathrm{dl}$ in women [15]. Hypertension was defined as seated blood pressure (BP) $\geq 140 / 90 \mathrm{~mm} \mathrm{Hg}$ or the current use of antihypertensive drugs [16]. Diabetes as fasting plasma glucose (FPG) $\geq 126 \mathrm{mg} / \mathrm{dl}$ or current use of antidiabetic drugs [17]. Global and central obesity were defined as body mass index (BMI) $\geq 30 \mathrm{Kg} / \mathrm{m}^{2}$ and waist circumference (WC) $\geq 94 \mathrm{~cm}$ for men and $\geq 80 \mathrm{~cm}$ for women, respectively [18] [19].

\section{Statistical Analyses}

Baseline characteristics were summarized as means and SDs for continuous variables normally distributed and median and interquartile range (IQR) for skewed variables; categorical variables as frequencies and percentages. Student $t$ test and Mann Whitney Wilcoxon test were used to compare means, as appropriate; Comparison of qualitative variables was performed using Chi square test. Multiple linear regression analysis was used to evaluate the relative contribution of sickle cell trait to the variation of hemoglobin level adjusting for potential confounders [Age, body mass index (BMI), diabetes duration, systolic (SBP) and diastolic (DBP) blood pressure, eGFR-MDRD, uric acid, proteinuria]. $\mathrm{P}<0.05$ defined the level of statistical significance. 


\section{Results}

Clinical and biological characteristics of the whole study population and according to hemoglobin genotype are summarized in Table 1 and Table 2. Of the 188 patients with CKD, 97 were women (52\%) and the mean age of the study group was $56 \pm 16$ years. They had in average Hb levels of $11 \pm 2.40 \mathrm{~g} / \mathrm{dl}$ and eGFR of $26 \pm 20$ $\mathrm{ml} / \mathrm{min} / 1.73 \mathrm{~m}^{2}$. CKD stages 3, 4 and 5 were present in 54\%, 15\% and 31\% of patients, respectively; hypertension (47\%), diabetes (29\%) and CGN (21\%) were the main underlying causes of CKD (Table 3). All patients were receiving conservative therapy based on BP control mainly with angiotensin converting enzyme inhibitors (72.8\%), glycemic control with insulin, dyslipidemia control with statins, symptomatic correction of anemia with iron, correction of water and electrolytes as well as acid base disturbances if present; although indicated, none of the patients was receiving erythropoietin. The proportion of SCT and HbAA patients receiving statins was $2.6 \%$ and $11.5 \%$, respectively; however, the difference was not statistically significant $(\mathrm{p}=0.075)$.

Table 1. Clinical characteristics of the CKD patients as a whole and according to hemoglobin genotype status.

\begin{tabular}{|c|c|c|c|c|}
\hline Variables & All group $n=188$ & HbAA n = 149 & HbAS n = 39 & $\mathrm{p}$ \\
\hline Gender, \% M & 48 & 44 & 67 & 0.012 \\
\hline $\mathrm{F}$ & 52 & 56 & 33 & \\
\hline Age, years & $56 \pm 16$ & $56 \pm 15$ & $55 \pm 17$ & 0.808 \\
\hline Smoking, \% & 4 & 3 & 8 & 0.339 \\
\hline Alcohol, \% & 7 & 8 & 7 & 0.433 \\
\hline BMI, $\mathrm{Kg} / \mathrm{m}^{2}$ & $26 \pm 6$ & $25 \pm 5$ & $26 \pm 5$ & 0.189 \\
\hline Overweight/Obesity, \% & 30 & 19 & 26 & 0.458 \\
\hline WC, cm & $92 \pm 16$ & $88 \pm 12$ & $89 \pm 13$ & 0.513 \\
\hline Central obesity, \% & 47 & 47 & 49 & 0.847 \\
\hline SBP, mm Hg & $151 \pm 26$ & $150 \pm 21$ & $158 \pm 29$ & 0.063 \\
\hline DBP, mm Hg & $85 \pm 15$ & $85 \pm 13$ & $86 \pm 10$ & 0.550 \\
\hline $\mathrm{PP}, \mathrm{mm} \mathrm{Hg}$ & $66 \pm 21$ & $64 \pm 20$ & $71 \pm 21$ & 0.180 \\
\hline
\end{tabular}

Data are expressed as mean \pm standard deviation or relative frequency in percent. Abbreviations: $\mathrm{M}$, male $\mathrm{F}$, female HbAA, normal hemoglobin HbAS, sickle cell trait BMI, body mass index WC, waist circumference SBP, systolic blood pressure DBP, diastolic blood pressure PP, pulse pressure.

Table 2. Biological characteristics of study patients as a whole and according to hemoglobin genotype status.

\begin{tabular}{|c|c|c|c|c|c|}
\hline Variables & $\mathrm{N}$ & All group $n=188$ & HbAA n = 149 & HbAS n = 39 & $\mathrm{p}$ \\
\hline $\mathrm{Hb}, \mathrm{g} / \mathrm{dl}$ & 188 & $11 \pm 2.40$ & $10 \pm 2.2$ & $09 \pm 1.8$ & 0.001 \\
\hline $\mathrm{Ht}, \%$ & 188 & $31 \pm 7.1$ & $30 \pm 5.4$ & $27 \pm 5.2$ & 0.001 \\
\hline Anemia, \% & 188 & 72 & 72 & 95 & 0.001 \\
\hline FPG, mg/dl & 188 & $135 \pm 93$ & $133 \pm 72$ & $141 \pm 78$ & 0.613 \\
\hline Uric acid, mg/dl & 157 & $7.5 \pm 2.8$ & $7.0 \pm 2.6$ & $9.5 \pm 2.7$ & 0.001 \\
\hline $\mathrm{TC}, \mathrm{mg} / \mathrm{dl}$ & 133 & $215 \pm 189$ & $220 \pm 209$ & $197 \pm 59$ & 0.570 \\
\hline LDL-c, mg/dl & 133 & $119 \pm 66$ & $121 \pm 68$ & $111 \pm 58$ & 0.467 \\
\hline HDL-c, mg/dl & 133 & $54 \pm 27$ & $53 \pm 28$ & $58 \pm 17$ & 0.398 \\
\hline $\mathrm{TG}, \mathrm{mg} / \mathrm{dl}$ & 133 & $125 \pm 67$ & $123 \pm 67$ & $135 \pm 70$ & 0.397 \\
\hline Creatinine, mg/dl & 188 & $7.2 \pm 8.4$ & $6.7 \pm 7.8$ & $8.8 \pm 1.08$ & 0.148 \\
\hline MDRD-GFR, $\mathrm{ml} / \mathrm{min} / 1.73 \mathrm{~m}^{2}$ & 188 & $26 \pm 20$ & $26 \pm 20$ & $23 \pm 18$ & 0.296 \\
\hline Dipstick-proteinuria, \% & 188 & 69 & 68 & 78 & 0.330 \\
\hline
\end{tabular}

Data are expressed as mean \pm standard deviation, median (range) or relative frequency in percent. Abbreviations: HbAA, normal hemoglobin HbAS, sickle cell trait Ht, hematocrit FBG, fasting plasma glucose TC, total cholesterol LDL-c, low-density lipoprotein cholesterol HDL-c, high-density lipoprotein cholesterol TG, triglycerides MDRD, modification of diet in renal disease GFR, glomerular filtration rate. 
Table 3. Stages and causes of chronic kidney disease in the study population as a whole and according to hemoglobin genotype status.

\begin{tabular}{|c|c|c|c|c|}
\hline Variables & All group $n=188$ & $\mathrm{HbAA} \mathrm{n}=149$ & HbAS n = 39 & $\mathrm{p}$ \\
\hline \multicolumn{5}{|l|}{ Stages, \% } \\
\hline 3 & 54 & 41 & 32 & 0.683 \\
\hline 4 & 15 & 20 & 26 & 0.305 \\
\hline 5 & 31 & 39 & 42 & 0.652 \\
\hline \multicolumn{5}{|l|}{ Causes, \% } \\
\hline AHT & 47 & 48 & 46 & 0.996 \\
\hline DM & 29 & 31 & 26 & 0.460 \\
\hline CGN & 21 & 19 & 28 & 0.313 \\
\hline HIVAN & 1 & 1 & 0 & - \\
\hline APKD & 2 & 3 & 0 & - \\
\hline Medications, \% & & & & 0.077 \\
\hline ACEI & 72.8 & 69.4 & 84.4 & \\
\hline ССВ & 8.2 & 9.5 & 3.1 & \\
\hline Statins & 9.6 & 11.5 & 2.6 & \\
\hline
\end{tabular}

Data are expressed as relative frequency in percent. Abbreviations: HbAA, normal hemoglobin HbAS, sickle cell trait AHT, arterial hypertension DM, diabetes mellitus CGN, chronic glomerulonephritis HIVAN, HIV-associated nephropathy APKD, autosomal polycystic kidney disease ACEI, angiotensin converting enzyme CCB, calcium channel blocker.

Sickle cell trait (HbAS) and anemia were present in 39 (21\%) and 135 (72\%) CKD patients, respectively. Despite similar eGFR ( $23 \pm 18$ for HbAS vs $26 \pm 20 \mathrm{ml} / \mathrm{min} / 1.73 \mathrm{~m}^{2}$ for HbAA, $\mathrm{p}=0.296$ ), HbAS patients had significantly ( $\mathrm{p}=0.001)$ lower Hb levels $(8.8 \pm 1.8$ vs $10 \pm 2.2 \mathrm{~g} / \mathrm{dl})$ and a higher $(95 \%$ vs $72 \%$; $\mathrm{p}=0.001)$ proportion of anemia than HbAA ones. They also had significantly elevated uric acid levels (9.50 \pm 2.7 vs $7.00 \pm$ $2.60 \mathrm{mg} / \mathrm{dl}, \mathrm{p}=0.001$ ) (Table 2).

In multiple linear regression analysis (Table 4), eGFR, BMI, SBP and sickle cell trait emerged as independent determinants of $\mathrm{Hb}$ levels; the model explained $50 \%\left(\mathrm{R}^{2} 0.50\right)$ of the variations in $\mathrm{Hb}$ levels. The presence of sickle cell trait was associated with $1.185 \mathrm{~g} / \mathrm{dl}$ decrease in $\mathrm{Hb}$ levels. Variables not included in the model were age, diabetes duration, DBP, uric acid and proteinuria.

\section{Discussion}

The main findings of the present post-hoc analysis are as follows; first, CKD patients with SCT had increased levels of uric acid; second, despite similar eGFR, they also had lower hemoglobin levels and a higher frequency of anemia than those with HbAA.

Elevated uric acid levels, component of the metabolic syndrome [20], are associated with insulin resistance and subsequent hyperinsulinemia [21] that could contribute to anemia in CKD through adipocytokine-induced oxidative stress and inflammation [22]. Since SCT could induce inflammatory responses and oxidative stress beyond those already initiate by CKD [6], higher uric acid levels in HbAS patients could translate an increased generation of reactive oxygen species and subsequent oxidative stress by the presence of this abnormal hemoglobin [23].

Lower hemoglobin levels in black patients with ESRD have been already reported in African Americans at the start of dialysis in comparison to other ethnic groups [1]. For some authors [4], this difference in hemoglobin levels could be reflective of an underlying hemoglobinopathy. In this regard, a higher prevalence of heterozygosity for $\mathrm{HbS}$ (HbAS) and $\mathrm{HbC}$ (HbAC) have been found in African-Americans with ESRD receiving renal replacement therapy [1] [4]. Our finding of an association between lower Hb levels and the presence of SCT in CKD patients raises question regarding the underlying mechanisms and clinical implications. 
Table 4. Determinants of hemoglobin levels in multiple linear regression analysis.

\begin{tabular}{ccccc}
\hline Variables & B & SE & p & $95 \%$ CI \\
\hline Constant & 7.740 & 1.772 & 0.001 & $4.210-11.283$ \\
BMI, Kg/m ${ }^{2}$ & 0.112 & 0.042 & 0.010 & $0.028-0.196$ \\
SBP, $\mathrm{mm} \mathrm{Hg}$ & -0.014 & 0.009 & 0.098 & $-0.031-(-) 0.003$ \\
eGFR, $\mathrm{ml} / \mathrm{min} / 1.73 \mathrm{~m}^{2}$ & 0.065 & 0.011 & 0.001 & $0.043-0.087$ \\
$\mathrm{Hb} \mathrm{AS}$ & -1.185 & 0.508 & 0.023 & $-2.199-(-) 0.171$ \\
\hline
\end{tabular}

$\mathrm{R}^{2}=0.50$. Abbreviations: B, regression coefficient SE, standard error CI, confidence interval BMI, body mass index SBP, systolic blood pressure eGFR, estimated glomerular filtration rate $\mathrm{Hb}$ AS, sickle cell trait $\mathrm{R}^{2}$, determination coefficient.

Several potential mechanisms could be advocated to explain our finding. First, although usually considered as a benign carrier state, individuals bearing either $\mathrm{HbS}$ or $\mathrm{HbC}$ have been found to develop clinical complications due to changes in red cell rigidity under situations of stress such as uremia and hemodialysis ultimately leading to low-grade sickling and subsequent hemolysis [5]. Indeed, uremic toxins can alter erythrocytes and predispose to sickling and hemolysis of red blood cells containing HbAS [6]. In hemodialysed patients, as blood travels through circuits, red cells exposed to lower temperature, partial pressure of oxygen and physical stressors of hemodialysis filter could experience sickling or dehydration; this transient sickling may lead to increased phosphatidylserine exposure on erythrocytes and reduced life span. Britain et al. [21] already reported that HbAS of hemodialysed patients exhibit an increase in red cell phosphatidylserine exposure. Second, chronic inflammation a feature of overt sickle cell disease (SCD) could be observed in a muted form with HbAS and impairs both iron utilization and erythropoeisis [6]. In addition, HbAS has been reported to induce inflammatory responses beyond those already experienced in hemodialysis [1].

The association of SCT with lower Hb levels in CKD patients may have some therapeutic implications. Indeed, observational studies have shown that African Americans patients under chronic hemodialysis require larger doses of erythropoiesis-stimulating agents (ESA) to achieve a similar level of Hb after adjustment for other modifying factors [1] [3]. Plausible explanatory mechanisms relative to this finding include chronic inflammation as aforementioned and antibodies against erythropoietin [1]. SCT could induce inflammatory responses beyond those already initiate by CKD and dialysis; these inflammatory responses could contribute to resistance to ESA by blunting iron use and erythropoiesis [6]. Antibodies against ESA may also contribute to an impaired ESA response [1]. It is however important to stress out that exposure to relatively high doses of ESA may raise safety concerns. Indeed, a landmark study demonstrated that normalizing hemoglobin in ESRD patients was associated with increasing mortality [22]. In addition, higher cardiovascular events and stroke have been recently reported with higher levels of hemoglobin and concurrently higher doses of ESA [23]. The Kidney Disease Outcome Quality Initiative (KDOQI) guidelines for anemia in CKD usually recommend a target hemoglobin of $11-12 \mathrm{~g} / \mathrm{dl}$ among patients under dialysis therapy, irrespective of the dose of ESA or intravenous iron [24]. Given the high mortality associated with ESA and higher hemoglobin levels, current practice in United States of America has shifted to a target of $10-12 \mathrm{~g} / \mathrm{dl}$ [25].

The results of the present post hoc analysis should be interpreted in the context of some limitations. First, it was a post-hoc analysis with a small sample size; second, ferritin and iron saturation capacity were not available to better characterize the types of anemia; third, the original study was a clinical-based cross-sectional study with a small sample size limiting the generalization of our findings; fourth, other types of hemoglobinopathies such as $\alpha$ or $\beta$-thalassemia, known to mitigate some of the effects of SCT were not assessed.

\section{Conclusion}

The present post-hoc analysis has shown that despite similar eGFR, CKD patients with SCT had significantly lower $\mathrm{Hb}$ levels and higher proportion of subjects with anemia. This finding does suggest the influential role of SCT in the pathogenesis and treatment of CKD-associated anemia.

\section{Acknowledgements}

The authors gratefully thank Dr Jeremie Muwonga for the use of the facilities at the National Laboratory of the 
National AIDS Control Program for the analysis of biological samples. We thank Prof Dr Leon Tshilolo for his outstanding help in the determination of hemoglobin genotypes at the Laboratory of Monkole Hospital. We are indebted to the Staff of the BDOM network for their commitment during the study. We thank Dr Kensese of General Hospital of Kinshasa for his help and all the study participants who by their consent had made the study possible. We would like to acknowledge all the staff of the University of Kinshasa Hospital, Saint Joseph Hospital especially Dr Josee Nkoyi, Monkole Hospital and Genal Hospital of Kinshasa.

\section{Authors' Contribution}

LFB conceived the study and wrote the manuscript; MTK conducted the study and revised the manuscript; MFIN revised database and the manuscript; MJR revised the study protocol and the manuscript; SEK revised the manuscript; KPK revised the study protocol, conducted statistical analysis and revised the manuscript; NNM revised the manuscript.

\section{References}

[1] Derebail, V.K., Nachman, P.H., Key, N.S., Ansede, H., Falk, R.J., Rosamond, W.D. and Kshirsagar, A.V. (2011) Variant Hemoglobin Phenotypes May Account for Differential Erythropoeisis-Stimulating Agent Dosing in AfricanAmerican Hemodialysis Patients. Kidney International, 80, 992-999. http://dx.doi.org/10.1038/ki.2011.247

[2] USRDS, USRDS (2009) Annual Data Report: Atlas of Chronic Kidney Disease and End-Stage Renal Disease in the United States. National Institutes of Health, National Institute of Diabetes and Digestive and Digestive and Kidney Diseases, Bethesda, MD.

[3] Lacson Jr., E., Rogus, J., Teng, M., Lazarus, J.M. and Hakim, R.M. (2008) The Association of Race with Erythropoetin Dose in Patients on Long-Term Hemodialysis. American Journal of Kidney Diseases, 52, 1104-1114. http://dx.doi.org/10.1053/j.ajkd.2008.07.026

[4] Derebail, V.K., Nachman, P.H., Key, N.S., Ansede, H., Falk, R.J., Rosamond, W.D. and Kshirsagar, A.V. (2010) High Prevalence of Sickle Cell Trait in African Americans with ESRD. Journal of the American Society of Nephrology, 21, 413-417. http://dx.doi.org/10.1681/ASN.2009070705

[5] Connes, P., Hue, O., Tripette, J. and Hardy-Dessomous, M.D. (2008) Blood Rheology Abnormalities and Vascular Cell Adhesion Mechanisms in Sickle Cell Trait Carriers during Exercise. Clinical Hemorheology and Microcirculation, 39, 179-184.

[6] Adamson, J.W. (2009) Hyporesponsiveness to Eryhtropoeisis Stimulating Agents in Chronic Kidney Disease: The Many Faces of Inflammation. Advances in Chronic Kidney Diseases, 16, 76-82. http://dx.doi.org/10.1053/j.ackd.2008.12.009

[7] Austin, H., Key, N.S., Benson, J.M., Lally, C., Dowling, N.F., Whitesett, C. and Hooper, W.C. (2007) Sickle Cell Trait and the Risk of Veinous Thromboembolism among Blacks. Blood, 110, 908-912. http://dx.doi.org/10.1182/blood-2006-11-057604

[8] Derebail, V.K., Lacson Jr., E.K., Kshirsagar, A.V., Key, N.S., Hogan, S.L., Hakim, R.M., et al. (2014) Sickle Trait in African-American Hemodialysis Patients and Higher Erythropoesis-Stimulating Agent Dose. Journal of the American Society of Nephrology, 25, 819-826. http://dx.doi.org/10.1681/ASN.2013060575

[9] Sumaili, E.K., Krzesinski, J.M., Zinga, C.V., Cohen, E.P., Delanaye, P., Munyanga, S.M., et al. (2009) Prevalence of Chronic Kidney Disease in Kinshasa: Results of a Pilot Study from the Democratic Republic of Congo. Nephrology Dialysis Transplantation, 24, 117-122. http://dx.doi.org/10.1093/ndt/gfn469

[10] Sumaili, E.K., Cohen, E.P., Zinga, C.V., Krzesinski, J.M., Pakasa, N.M. and Nseka, N.M. (2009) High Prevalence of Undiagnosed Chronic Kidney Disease among At-Risk Population in Kinshasa, the Democratic Republic of Congo. BMC Nephrology, 10, 18. http://dx.doi.org/10.1186/1471-2369-10-18

[11] Tshilolo, L., Aissi, L.M., Lukusa, D., Kinsiama, C., Wembonyama, S., Gulbis, B. and Vertongen, F. (2009) Neonatal Screening for Sickle Cell Anaemia in the Democratic Republic of the Congo: Experience from a Pioneer Project on 31 204 Newborns. Journal of Clinical Pathology, 62, 35-38. http://dx.doi.org/10.1136/jcp.2008.058958

[12] Mukendi, T.K., Lepira, F.B., Makulo, J.R.R., Sumaili, K.E., Kayembe, P.K. and Nseka, M.N. (2015) Sickle Cell Trait May Not Be Associated with Chronic Kidney Disease in Black Patients. A Clinical Based Cross-Sectional Study. Cardiovascular Journal of Africa, 26, 125-129.

[13] Levey, A.S., Greene, T. and Kusek, J.W. (2000) A Simplified Equation to Predict Glomerular Filtration Rate from Serum Creatinine. Journal of the American Society of Nephrology, 11, A0828.

[14] K/DOQI. Clinical Practical Guidelines for Chronic Kidney Disease (CKD) (2002) Kidney Disease Outcome Quality Initiative. American Journal of Kidney Diseases, 39, S22-S26. 
[15] Dimitrieva, O., de Lusignan, S. and Goldsmith, D. (2013) Association of Anemia in Primary Care Patients with Chronic Kidney Disease: Cross-Sectional Study of Quality Improvement in Chronic Kidney Disease (AICKD) Trial Data. BMC Nephrology, 14, 24. http://dx.doi.org/10.1186/1471-2369-14-24

[16] Mansia, G., De Backer, G., Dominiczak, A., Cikova, R., Fagard, R., Germano, G., et al. (2007) Guidelines for the Management of Arterial Hypertension: The Task Force for the Management of Arterial Hypertension of the European Society of Hypertension (ESH) and of the European Society of Cardiology (ESC). Blood Press, 16, 135-232. http://dx.doi.org/10.1080/08037050701461084

[17] The Expert Committee on the Diagnosis and Classification of Diabetes Mellitus (2003) Report of Expert Committee on the Diagnosis of and Classification of Diabetes Mellitus. Diabetes Care, 26, S5-S20. http://dx.doi.org/10.2337/diacare.26.2007.S5

[18] World Health Organization (WHO) (2000) The Problem of Overweight and Obesity: Preventing and Managing the Global Epidemic. Report Series 894, Geneva, 537.

[19] Alberti, K.G., Eckel, R.H., Grundy, S.M., Zimmet, P.Z., Cleeman, J.L., Donato, K.A., et al. (2009) Harmonizing the Metabolic Syndrome. A Joint Interim Statement of the International Diabetes Federation Task Force on Epidemiology and Prevention, National Heart, Lung, and Blood Institute, American Heart Association, World Heart Federation, International Atherosclerosis Society, and International Association for the Study of Obesity. Circulation, 120, 16401645. http://dx.doi.org/10.1161/CIRCULATIONAHA.109.192644

[20] Glantzounis, G.K., Tsimoyiannis, E.C., Kappas, A.M. and Galaris, D.A. (2005) Uric Acid and Oxidative Stress. Current Pharmaceutical Design, 11, 4145-4151. http://dx.doi.org/10.2174/138161205774913255

[21] Britain, J., Derebail, V.K., Mooberry, M.J., Ataga, K.I., Kshirsagar, A.V. and Key, N.S. (2010) Increased Red Cell Phosphatidylserine Exposure Correlates with End-Stage Renal Disease. Blood, 116, 2665.

[22] Besarab, A., Bolton, W.K., Browne, J.K., Egrie, J.C., Nissenson, A.R., Okamoto, D.M., et al. (1998) The Effects of Normal as Compared with Low Hematocrit Values in Patients with Cardiac Disease Who Are Receiving Hemodialysis and Epoietin. The New England Journal of Medicine, 339, 584-590. http://dx.doi.org/10.1056/NEJM199808273390903

[23] Drueke, T.B., Locatteli, F., Clyne, N., Eckart, K.U., Macdougall, I.C., Tsakiris, D., et al. (2006) Normalization of Hemoglobin Level in Patients with Chronic Kidney Disease and Anemia. The New England Journal of Medicine, 355, 2071-2084. http://dx.doi.org/10.1056/NEJMoa062276

[24] KDOQI (2007) KDOQI Clinical Practice Guideline and Clinical Practice Recommendations for Anemia in Chronic Kidney Disease: 2007 Update of Hemoglobin Target. American Journal of Kidney Diseases, 50, 471-530. http://dx.doi.org/10.1053/j.ajkd.2007.06.008

[25] Federal Register (2010) Thursday, 12 August 2010 Proposed Rules. http://www.cms.gov/ESRDQualityImproveInit

\section{Submit or recommend next manuscript to SCIRP and we will provide best service for you:}

Accepting pre-submission inquiries through Email, Facebook, LinkedIn, Twitter, etc.

A wide selection of journals (inclusive of 9 subjects, more than 200 journals)

Providing 24-hour high-quality service

User-friendly online submission system

Fair and swift peer-review system

Efficient typesetting and proofreading procedure

Display of the result of downloads and visits, as well as the number of cited articles

Maximum dissemination of your research work

Submit your manuscript at: http://papersubmission.scirp.org/ 